\title{
Fermentação e Degradabilidade Ruminal em Bovinos Alimentados com Resíduos de Mandioca e Cana-de-Açúcar ensilados com Polpa Cítrica Peletizada ${ }^{1}$
}

\author{
Roselene Nunes da Silveira ${ }^{2}$, Telma Teresinha Berchielli ${ }^{3}$, Djalma de Freitas ${ }^{2}$, Ana Karina Dias \\ Salman ${ }^{4}$, Pedro de Andrade ${ }^{3}$, Alexandre Vaz Pires ${ }^{5}$, Juliano José de Resende Fernandes ${ }^{6}$
}

RESUMO - O presente trabalho foi conduzido com o objetivo de avaliar a degradabilidade ruminal da matéria seca (MS), fibra em detergente neutro (FDN) e amido, além de pH, amônia e ácidos graxos voláteis ruminais, em bovinos alimentados com silagens de milho (SMi), de raspa de mandioca com polpa cítrica (SRp), de casca de mandioca com polpa cítrica (SCc) e de cana-de-açúcar com polpa cítrica (SCn). Foram utilizados quatro novilhos, mestiços, castrados, canulados no rúmen e duodeno, em quatro períodos experimentais, com 11 dias de adaptação à dieta e oito dias de coleta. O delineamento experimental foi o quadrado latino $4 \mathrm{x} 4$. Foram adotados oito horários para a incubação das silagens: 3, 6, 12, 24, 48, 72, 96 e 120 horas. A SRp apresentou maior degradação efetiva (Kp 5\%) da MS e da FDN (48,44 e 45,78\%, respectivamente), quando comparada com a SMi (45,50 e 23,75\%), a SCc (43,87 e 24,20\%) e a SCn (40,76 e 25,78\%). Para todos os tratamentos, o $\mathrm{pH}$ e a concentração de $\mathrm{N}-\mathrm{NH}_{3}$ ruminal foram adequados para o crescimento dos microrganismos ruminais. Os valores de AGV para os tratamentos de SMi, SRp e SCc foram semelhantes entre si e superiores aos do tratamento com SCn.

Palavras-chave: cana-de-açúcar, degradabilidade, mandioca, parâmetros ruminais silagem.

\section{Ruminal Fermentation and Degradability in Bovine Fed Diet with Cassava Residue and Sugar Cane Ensiled with Pelleted Citrus Pulp}

\begin{abstract}
The objective of this work was to evaluate the dry matter (DM), neutral detergente fiber (NDF) and starch ruminal degradability besides $\mathrm{pH}, \mathrm{N}-\mathrm{NH}_{3}$ and valatile fatty acids (VFA) in bovines fed diet with corn (CS), cassava meal (CMS), cassava hull (CHS), and sugar cane (SCS). The CMS, CHS and SCS were ensiled with citrus pulp (CPP). Four crossbred, castrated, rumen and duodenum cannulated steers were used in four experimental periods, with 11 days for diet adaptation and 8 days for sampling. The experimental design was 4x4 Latin Square. There were eight incubations times: 3, 6, 12, 24, 48, 72, 96 and 120 hours. The CMS showed higher DM, and NDF effective degradation (Kp 5\%) (48.44 and 45.78\%, respectively) than CS (45.50, 23.75\%), CHS (43.87, $24.20 \%)$ and SCS $(40.76,25.78 \%)$. For all the treatments, the $\mathrm{pH}$ and the ruminal concentration of $\mathrm{N}_{-} \mathrm{NH}_{3}$ were appropriate for the growth of the rumen microrganisms. The VFA values of the CS, CMS and CHS treatments were similar among themselves and higher than the SCS treatment.
\end{abstract}

Key Words: cassava, degradability, ruminal parameters, silage, sugar cane

\section{Introdução}

As condições ideais para adequada fermentação ruminal de bovinos seriam as altas taxas de digestão da fibra, presença de ácidos graxos, produção de amônia e metano, além de elevada síntese microbiana (Arcury \& Mattos, 1992). Entretanto, a manipulação de algumas dessas características, em diferentes dietas, é limitada pelo efeito prejudicial, que pode causar em outros aspectos da fermentação ruminal, sobre o desempenho dos microrganismos e, conseqüentemente, do animal.
Alguns subprodutos da indústria utilizados nas dietas têm potencial para atender estas condições desejáveis. Entre estes, destaca-se a polpa cítrica peletizada, resultante da produção industrial de suco de laranja; os subprodutos da indústria de farinha de mandioca, como a raspa de mandioca, o resíduo da fabricação do polvilho e a casca de mandioca constituída por cascas; e as pontas de mandioca residuais, que se caracterizam também como fonte de energia, por conterem carboidratos de alta degradabilidade ruminal.

Atualmente, um dos grandes problemas encontrados pelas indústrias em geral é a dificuldade de

\footnotetext{
1 Parte da Dissertação de Mestrado do primeiro autor.

${ }^{2}$ Aluno do curso de Pós-Graduação em Zootecnia, FCAV/UNESP - Jaboticabal (SP). E.mail: silveira@fcav.unesp.br; djalma@fcav.unesp.br

3 Professor da FCAV/UNESP - Jaboticabal -SP. Pesquisador do CNPq. E.mail: ttberchi@fcav.unesp.br

${ }^{4}$ Aluno do curso de Pós-Graduação em Zootecnia, FMVZ/UNESP - Botucatu (SP). E.mail: akadias@fcav.unesp.br

${ }^{5}$ Professor da Esalq - Piracicaba - SP.

${ }^{6}$ Aluno do curso de Pós-Graduação em Zootecnia, ESALQ - Piracicaba (SP).
} 
escoamento de resíduos, que são responsáveis em parte pela contaminação ambiental, devido à grande quantidade acumulada na forma de lixo. Assim, a ensilagem dos resíduos de mandioca é uma opção encontrada para armazenar e tem sido utilizada aleatoriamente por muitos produtores. No entanto, estes resíduos para serem usados para ruminantes devem ser secos ou ensilados para evitar possíveis riscos de intoxicação. Como em sistemas intensivos a secagem torna-se inviável, devido à quantidade de mão-de-obra disponível, espaço físico, tempo gasto para o manuseio do resíduo e custo, a melhor alternativa ainda seria a ensilagem.

Para caracterizar a degradabilidade ruminal dos nutrientes dos alimentos, o AFRC (1995) adotou a técnica de degradação in situ como um método padrão, pois este apresenta resultados semelhantes àqueles obtidos pela técnica in vivo. Como as diferenças nas características de degradação dos alimentos repercutem sobre a dinâmica e o equilíbrio dos nutrientes disponíveis para os microrganismos do rúmen (McCarthy et al., 1989), o estudo da cinética de degradação ruminal de diferentes alimentos tem mostrado resultados que possibilitam aos nutricionistas o balanceamento de rações, visando a maximização da eficiência de utilização energética e protéica dos microrganismos e do ruminante (Andrade, 1994; Valadares Filho, 1994).

Este trabalho foi conduzido com o objetivo de avaliar a degradabilidade ruminal da matéria seca (MS), fibra em detergente neutro (FDN), amido e parâmetros ruminais, como $\mathrm{N}-\mathrm{NH}_{3}, \mathrm{pH}$ e ácidos graxos voláteis, em bovinos alimentados com silagens de milho, de resíduos de mandioca e de cana-deaçúcar adicionados com polpa cítrica peletizada.

\section{Material e Métodos}

Foram utilizados quatro novilhos mestiços (Holandês $\mathrm{x}$ Zebu), castrados, com peso vivo médio de $272 \mathrm{~kg}$ e aproximadamente 18 meses de idade, identificados com brincos numerados e canulados no rúmen e duodeno. Os animais foram alojados em baias individuais cobertas, com cocho individual para alimentação e bebedouro comum a duas baias. No período pré-experimental os animais foram vermifugados (Ivermectina) e vacinados (febre aftosa).

O experimento teve duração de 76 dias, tendo quatro períodos com duração de 19 dias cada, sendo 10 dias para a adaptação dos animais à dieta e 9 dias para as coletas. No final de cada período, os animais foram pesados para o ajuste necessário das quantidades dos alimentos a serem fornecidas.

Foram utilizadas dietas constituídas de raspa de mandioca, casca de mandioca e cana-de-açúcar adicionadas de polpa cítrica, onde a polpa cítrica foi utilizada para ajustar a matéria seca (MS) das silagens para $30-35 \%$ de MS (Tabela 1), que foram ensiladas em silos experimentais de tubos de concreto de aproximadamente 3 metros de altura por 1,5 metros de diâmetro, com exceção da silagem de milho, que foi armazenada em silo tipo poço.

Após 45 dias de vedação, os silos foram abertos e amostrados para determinação da matéria seca (MS), matéria mineral (MM), proteína bruta (PB), fibra em detergente neutro (FDN) e ácido (FDA) (AOAC, 1990), pH e amido, segundo a metodologia enzimática de Poore et al. (1989), modificada para leitura de glicose por colorimetria (Pereira \& Rossi Jr., 1995).

Tabela 1 - Proporção da polpa cítrica utilizada para o ajuste de matéria seca das silagens de casca de mandioca, de raspa de mandioca e cana-de-açúcar com polpa cítrica

Table 1 - Proportion of citrus pulp used to balance the dry matter of cassava hull, cassava meal and sugarcane plus citric pulp silages

\begin{tabular}{|c|c|c|c|c|}
\hline \multirow[t]{2}{*}{$\begin{array}{l}\text { Silagem } \\
\text { Silage }\end{array}$} & \multicolumn{4}{|c|}{$\begin{array}{c}\text { Ingrediente }(\%) \\
\text { Ingredient }(\%) \\
\end{array}$} \\
\hline & $\begin{array}{l}\mathrm{Cc}^{1} \\
\mathrm{Ch}^{1}\end{array}$ & $\begin{array}{l}\mathrm{Rp}^{2} \\
\mathrm{Cm}^{2}\end{array}$ & $\begin{array}{l}\mathrm{Cn}^{3} \\
\mathrm{Sc} c^{3}\end{array}$ & $\begin{array}{l}\mathrm{Pc}^{4} \\
\mathrm{Cp}^{4}\end{array}$ \\
\hline $\begin{array}{l}\text { Silagem de casca de mandioca }+ \text { polpa cítrica } \\
\text { Cassava hull silage }+ \text { citric pulp }\end{array}$ & 63,7 & - & - & 36,3 \\
\hline $\begin{array}{l}\text { Silagem de raspa de mandioca }+ \text { polpa cítrica } \\
\text { Cassava meal silage }+ \text { citric pulp }\end{array}$ & - & 53,4 & - & 46,6 \\
\hline $\begin{array}{l}\text { Silagem de cana-de-açúcar }+ \text { polpa cítrica } \\
\text { Sugarcane silage }+ \text { citric pulp }\end{array}$ & - & - & 55,4 & 44,6 \\
\hline
\end{tabular}

${ }^{1}$ Casca de mandioca, ${ }^{2}$ raspa de mandioca, ${ }^{3}$ cana-de-açúcar, ${ }^{4}$ polpa cítrica.

${ }^{1}$ Cassava hull, ${ }^{2}$ cassava meal, ${ }^{3}$ sugarcane, ${ }^{4}$ citric pulp.

R. Bras. Zootec., v.31, n.2, p.793-801, 2002 
A partir da composição química das silagens (Tabela 2), foi possível formular as quatro dietas que constituíram os tratamentos, sendo que uma delas serviu como dieta basal (silagem de milho + farelo de soja), participando com aproximadamente $60 \%$ da MS, em que o farelo de soja foi a fonte protéica das dietas dos tratamentos com as silagens de casca e de raspa com polpa cítrica, as quais foram utilizadas como concentrados energéticos. O potencial de nitrogênio degradável dessas duas dietas foi ajustado utilizando-se a uréia, conforme o AFRC (1995). A silagem de cana-de-açúcar com polpa cítrica teve apenas o potencial de nitrogênio degradável ajustado com uréia, sendo fornecida exclusivamente.

As dietas foram fornecidas duas vezes ao dia, às 7 e $13 \mathrm{~h}$, sendo as sobras retiradas, pesadas e amostradas pela manhã, diariamente, sendo a composição química e a proporção dos ingredientes das dietas (\% MS) apresentadas na Tabela 3. O consumo foi ajustado buscando manter as sobras em torno de $10 \%$ do oferecido. Além disso, houve o fornecimento diário de $70 \mathrm{~g}$ de sal mineral/animal/dia.

Para o ensaio de degradabilidade in situ, foram confeccionadas bolsas de náilon ( 50 micras) medindo $7 \times 14 \mathrm{~cm}$ e fechadas em seladora. Aproximadamente cinco gramas de silagens secas e moídas foram acondicionados nas bolsas, as quais foram fixadas em diferentes pontos de uma corrente de metal de $50 \mathrm{~cm}$ de comprimento presa à tampa da cânula por uma das extremidades. Em cada um dos oito períodos de incubação $(3,6,12,24,48,72,96$ e 120 horas) foram colocadas duas bolsas até 48 horas e nos horários de
72, 96 e 120 horas, três bolsas, totalizando 19 bolsas por animal. Os horários mais longos foram incubados em triplicatas, visando obter maior quantidade de resíduo para as análises laboratoriais.

Antes da incubação, as bolsas de náilon foram imersas em água, à temperatura ambiente, por uma hora. A fração solúvel foi obtida submergindo duas bolsas de náilon de cada material incubado em água por 1 hora a $39^{\circ} \mathrm{C}$, lavadas manualmente e, posteriormente, secas em estufa a $65^{\circ} \mathrm{C}$ por 48 horas. As bolsas foram colocadas no rúmen simultaneamente e depois retiradas do menor para o maior tempo. Em seguida, foram lavadas manualmente até observar a água transparente e, posteriormente, secas em estufa a $65^{\circ} \mathrm{C}$ por 48 horas (Furlan, 1998).

Os resíduos de degradação de todas as silagens incubadas foram analisadas para MS e FDN (AOAC, 1990). Com exceção dos resíduos de degradação da silagem de cana-de-açúcar, todos os outros foram analisados para teor de amido.

As degradabilidades potenciais (DP) foram calculadas segundo o modelo DP $=\mathrm{a}+\mathrm{b}(1-\mathrm{e}-\mathrm{c}$.t $)$, para t $>$ L, proposto por Mehrez \& ØRskov (1977), em que: a refere-se à fração imediatamente solúvel; b, à fração insolúvel potencialmente degradável; c, à taxa constante de degradação da fração b; t, ao tempo de incubação; e L, ao tempo de colonização.

As degradabilidades efetivas (DE) foram calculadas pela equação proposta por $\varnothing$ rskov \& McDonald (1979), considerando-se as taxas de passagem de 2 e $5 \% /$ hora, sendo $\mathrm{DE}=\mathrm{a}+\mathrm{b} . \mathrm{c} /(\mathrm{c}+\mathrm{k})$, em que a é a fração imediatamente solúvel; $b$, a fração insolúvel

Tabela 2 -Composição química dos ingredientes das dietas (\% MS) e pH

Table 2 - Chemical composition of ingredient of the diets (\%DM) and $\mathrm{pH}$

\begin{tabular}{|c|c|c|c|c|c|c|c|}
\hline $\begin{array}{l}\text { Ingrediente } \\
\text { Ingredient }\end{array}$ & $\begin{array}{l}\mathrm{MS} \\
D M\end{array}$ & $\begin{array}{l}\mathrm{MM} \\
A S H\end{array}$ & $\begin{array}{l}\mathrm{PB} \\
C P\end{array}$ & $\begin{array}{l}\mathrm{FDN} \\
N D F\end{array}$ & $\begin{array}{l}\mathrm{FDA} \\
A D F\end{array}$ & $\begin{array}{l}\text { Amido } \\
\text { Starch }\end{array}$ & $\begin{array}{l}\mathrm{pH} \\
\mathrm{pH}\end{array}$ \\
\hline $\begin{array}{l}\mathrm{SMi}^{1} \\
C S^{1}\end{array}$ & 31,07 & 4,98 & 8,51 & 50,61 & 28,52 & 18,80 & 4,37 \\
\hline $\begin{array}{l}\mathrm{SRp}^{2} \\
C M S^{2}\end{array}$ & 31,12 & 6,16 & 5,87 & 27,14 & 21,38 & 27,68 & 3,82 \\
\hline $\begin{array}{l}\mathrm{SCc}^{3} \\
C H S^{3}\end{array}$ & 30,92 & 13,92 & 5,80 & 50,25 & 42,98 & 15,90 & 4,29 \\
\hline $\begin{array}{l}\mathrm{SCn}^{4} \\
S C S^{4}\end{array}$ & 29,10 & 5,03 & 5,80 & 55,15 & 35,69 & - & 4,02 \\
\hline $\begin{array}{l}\mathrm{FS}^{5} \\
\text { Soybean meal }\end{array}$ & 90,54 & 6,36 & 48,23 & 18,55 & - & - & - \\
\hline $\begin{array}{l}\text { Uréia } \\
\text { Urea }\end{array}$ & 99,00 & - & 275,00 & - & - & - & - \\
\hline
\end{tabular}

${ }^{1}$ Silagem de milho; ${ }^{2}$ Silagem de raspa de mandioca com polpa cítrica; ${ }^{3}$ Silagem de casca de mandioca com polpa cítrica; ${ }^{4}$ Silagem de cana-de-açúcar com polpa cítrica; ${ }^{5}$ Farelo de soja

${ }^{1}$ Corn silage; ${ }^{2}$ Cassava meal ensiled with citrus pulp; ${ }^{3}$ Cassava hull ensiled with citrus pulp; ${ }^{4}$ Sugarcane ensilated with citrus pulp. 
Tabela 3 -Proporção dos ingredientes, composição química das dietas (\% MS) e ingestão de matéria seca (MS) Table 3 - Proportion of ingredient, chemical composition of the diets (\%DM) and dry matter intake (DM)

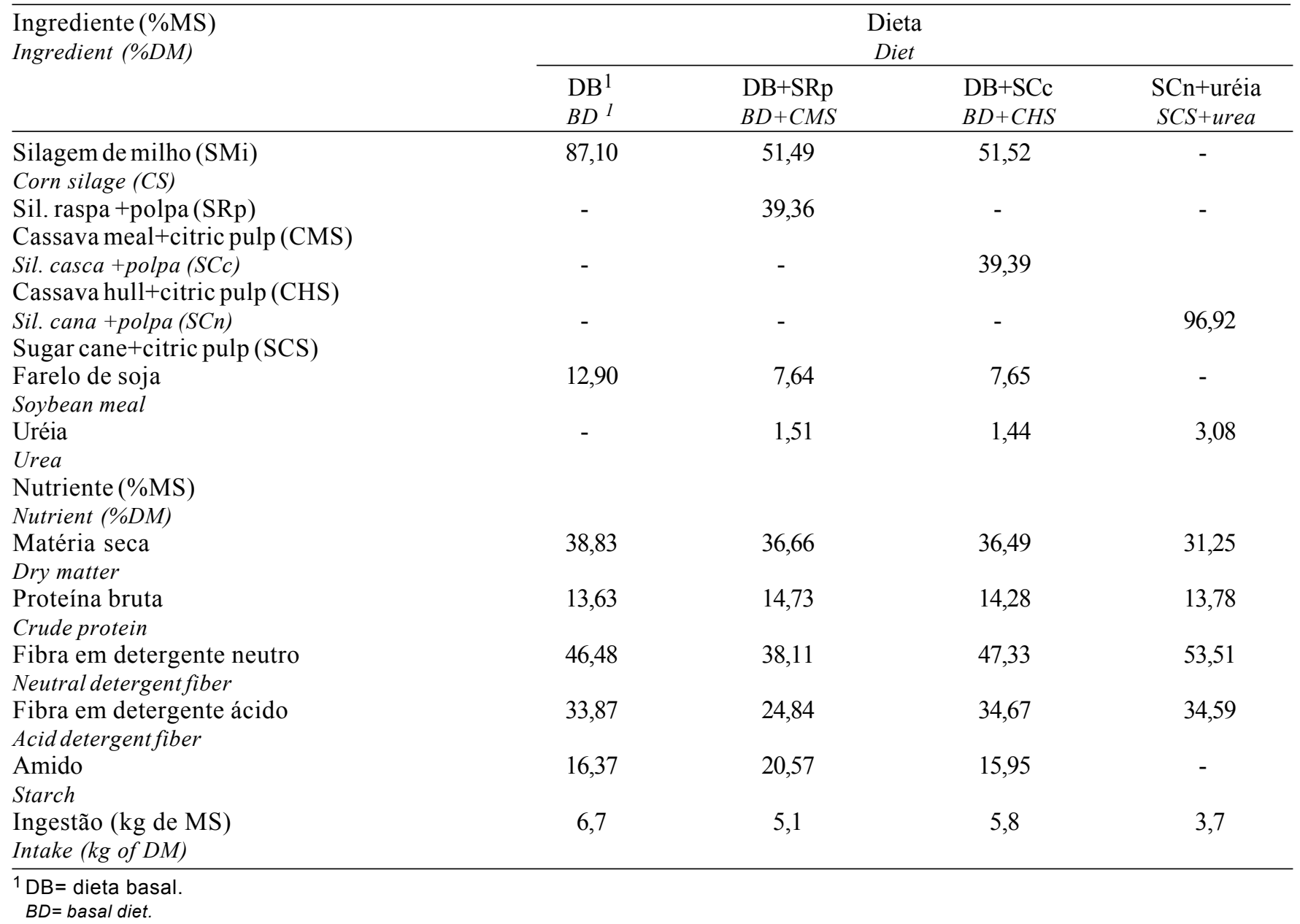

potencialmente degradável; c, a taxa constante de degradação da fração b; e k, a taxa de passagem da fração sólida do conteúdo ruminal.

Após o ensaio de degradação in situ, iniciaram-se as coletas de fluido ruminal para a determinação de $\mathrm{N}-\mathrm{NH}_{3}$ (Preston, 1986), pH e ácidos graxos voláteis. As coletas foram realizadas durante três dias, nos horários de 3, 4,5, 6e 7 horas após a alimentação. O fluido ruminal foi coletado tomando-se uma porção do conteúdo ruminal e comprimindo-a em tecido de algodão.

O delineamento estatístico utilizado foi o quadrado latino $4 \times 4$ (quatro animais e quatro períodos) com quatro tratamentos, correspondentes às silagens de milho, de raspa e de casca de mandioca com polpa cítrica e de cana-de-açúcar com polpa cítrica. A análise de variância e a comparação de médias pelo teste de Tukey a 5\% foram obtidas por intermédio do PROCGLMdo Statistical Analisis Sistem (SAS, 1985).

O modelo matemático foi:

$$
\mathrm{Y}_{\mathrm{ijk}}=\mathrm{m}+\mathrm{A}_{\mathrm{i}}+\mathrm{P}_{\mathrm{j}}+\mathrm{C}_{\mathrm{k}}+\mathrm{e}_{\mathrm{ijk}}
$$

em que: $Y_{\mathrm{ijk}}=$ observação do efeito do tratamento k, no período $\mathrm{j}$, no animal $\mathrm{i} ; \mathrm{m}=$ média geral; $\mathrm{A}_{\mathrm{i}}=$ efeito do animal $\mathrm{i} ; \mathrm{P}_{\mathrm{j}}=$ efeito do período $\mathrm{j} ; \mathrm{C}_{\mathrm{k}}=$ efeito do tratamento $\mathrm{k} ; \mathrm{e}_{\mathrm{ijk}}=$ erro aleatório associado a cada observação.

Os dados de $\mathrm{pH}, \mathrm{N}-\mathrm{NH}_{3}$ ruminal e degradação in situ foram dispostos em esquema de parcelas subdivididas, com os tempos de amostragem nas subparcelas.

\section{Resultados e Discussão}

Os resultados do ensaio de degradação in situ da matéria seca (MS), fibra em detergente neutro (FDN) e amido das silagens estão apresentados na Tabela 4, na qual se observa que a fração solúvel (a) da MS da silagem de casca de mandioca com polpa cítrica (SCc) foi menor que a encontrada nos demais tratamentos e, conseqüentemente, a fração insolúvel potencialmente degradável (b) foi maior. As degradabilidades potencial (DP) e efetiva (DE) da 
Tabela 4 -Frações solúvel (a) e insolúvel potencialmente degradável (b), degradabilidades potencial (DP) e efetiva (DE), considerando taxas de passagem de 2 e $5 \% / h$, e taxa de degradação da fração b (Kd) da MS, FDN e amido das silagens

Table 4 - Soluble (a) and insoluble pontentially degradable (b) fractions, potential (PD) and effective (ED) degradation, for passage rate of 2 and $5 \% / h$, and degradation rate of the $b$ fraction $(K d)$ of the $D M, N D F$ and starch of the silages

\begin{tabular}{|c|c|c|c|c|c|c|c|}
\hline & \multirow[t]{2}{*}{$\mathrm{a}$} & \multirow[t]{2}{*}{$\begin{array}{l}\mathrm{b} \\
\%\end{array}$} & \multirow[t]{2}{*}{$\begin{array}{l}\text { DP } \\
P D\end{array}$} & \multicolumn{2}{|c|}{$\begin{array}{l}\mathrm{DE} \\
E D\end{array}$} & \multirow{2}{*}{$\begin{array}{l}\mathrm{Kd} \\
\% / \mathrm{h}\end{array}$} & \multirow[t]{2}{*}{$\mathrm{r}^{2}$} \\
\hline & & & & Kp $2 \%$ & Kp 5\% & & \\
\hline & \multicolumn{7}{|c|}{$\begin{array}{l}\text { Matéria seca }(\mathrm{MS}) \\
\text { Dry matter }(D M)\end{array}$} \\
\hline $\begin{array}{l}\text { SMi } \\
C S\end{array}$ & 31,92 & 33,04 & 64,96 & 52,92 & 45,50 & 3,49 & 0,94 \\
\hline $\begin{array}{l}\text { SRp } \\
C M S\end{array}$ & 26,01 & 39,90 & 65,91 & 56,43 & 48,44 & 6,42 & 0,96 \\
\hline $\begin{array}{l}\mathrm{SCc} \\
\mathrm{CHS}\end{array}$ & 11,53 & 65,07 & 76,60 & 57,85 & 43,87 & 4,94 & 0,86 \\
\hline \multirow[t]{2}{*}{$\begin{array}{l}\mathrm{SCn} \\
S C S\end{array}$} & 23,16 & 40,83 & 63,99 & 49,89 & 40,76 & 3,79 & 0,97 \\
\hline & \multicolumn{7}{|c|}{$\begin{array}{l}\text { Fibra em detergente neutro (FDN) } \\
\text { Neutral detergent fiber }(N D F)\end{array}$} \\
\hline $\begin{array}{l}\text { SMi } \\
C S\end{array}$ & - & 72,63 & 72,63 & 39,84 & 23,75 & 2,43 & 0,89 \\
\hline $\begin{array}{l}\text { SRp } \\
C M S\end{array}$ & - & 83,13 & 83,13 & 62,68 & 45,78 & 6,13 & 0,92 \\
\hline $\begin{array}{l}\mathrm{SCc} \\
\mathrm{CHS}\end{array}$ & - & 61,31 & 61,31 & 38,00 & 24,20 & 3,26 & 0,82 \\
\hline $\mathrm{SCn}$ & - & 70,86 & 70,86 & 41,70 & 25,78 & 2,86 & 0,94 \\
\hline$S C S$ & & & & $\begin{array}{l}\text { Amido } \\
\text { Starch }\end{array}$ & & & \\
\hline $\begin{array}{l}\text { SMi } \\
C S\end{array}$ & 25,94 & 74,05 & 99,99 & 86,69 & 73,81 & 9,14 & 0,83 \\
\hline $\begin{array}{l}\text { SRp } \\
C M S\end{array}$ & 40,76 & 59,17 & 99,93 & 92,89 & 85,00 & 14,82 & 0,93 \\
\hline $\begin{array}{l}\mathrm{SCc} \\
\mathrm{CHS}\end{array}$ & 18,87 & 81,00 & 99,87 & 82,76 & 67,39 & 7,47 & 0,89 \\
\hline
\end{tabular}

MS da SCc, considerando-se as taxas de passagem (Kp) de $2 \% / \mathrm{h}$, foram maiores, mesmo com uma taxa de degradação $(\mathrm{Kd})$ menor que a da silagem de raspa de mandioca com polpa cítrica (SRp) e maior que a das silagens de milho (SMi) e de cana-de-açúcar com polpa cítrica $(\mathrm{SCn})$.

Para a SMi foram observados menores valores da fração solúvel (a) e da degradabilidade efetiva (DE) $(\mathrm{Kp} 5 \% / \mathrm{h})$ e maior taxa de degradação da fração b (kd) da MS que os obtidos no estudo de Martins (1999), que foram de 45,2\%, 54,8\% e 1,1\%/h, respectivamente.

Não foram encontrados na literatura valores dos parâmetros de degradação das silagens de casca, de raspa e de cana-de-açúcar com polpa cítrica. Por isso, os resultados observados no presente estudo foram comparados com os obtidos para estes alimentos sem que os mesmos tenham sido ensilados.

As frações $a$ da MS da SRp, da SCc e da SCn foram menores que aquelas observadas para MS de raspa de mandioca desidratada de 55,6\% (Martins, 1999), casca de mandioca desidratada de $28 \%$ (Caldas Neto, 2000) e para a cana-de-açúcar fresca picada (46,82\%) (Franzolin \& Franzolin, 2000).Conseqüentemente, as frações b da MS das SRp, SCc e $\mathrm{SCn}$ foram maiores que as encontradas na literatura para estes alimentos não ensilados, de 37,9\% (Martins, 1999), 59,7\% (Caldas Neto, 2000) e 31,00\% (Franzolin \& Franzolin, 2000).

Estes valores menores das frações $a$ e $b$ da MS 
das silagens podem estar associados ao processo fermentativo, pois este influencia a qualidade e a composição bromatológica da silagem, por meio da ação de enzimas já existentes nos alimentos ou produzidas pelas bactérias fermentativas durante $o$ processo de ensilagem.

Pode-se observar que a fração $b$ da FDN da SCc foi menor em comparação às dos outros tratamentos. $\mathrm{O}$ mesmo pode ser observado para a DP e as DE (Kp 2 e $5 \% / \mathrm{h}$ ), que também foram menores, apesar de a Kd da fração $b$ da FDN da SCc ter apresentado um valor intermediário entre as $\mathrm{SMi}$ e $\mathrm{SCn}$. Isto pode demonstrar que a qualidade da fibra da SCc foi inferior às das demais silagens estudadas.

Nota-se que, apesar de a SRp ter apresentado menor teor de FDN (Tabela 2), a DP e as DE (Kp 2 e 5\%/h) da FDN foram maiores que as das outras silagens, o que pode refletir a melhor qualidade da fibra da SRp.

A DP da FDN da SCn foi próxima aos 70,3\% encontrados por Franzolin \& Franzolin (2000), que trabalharam com cana-de-açúcar fresca picada. Os valores da fração $b$, DE e kd do presente trabalho apresentam valores maiores que os encontrados por Franzolin \& Franzolin (2000), de 52,91\%; 31,39\%; e $1,8 \% / \mathrm{h}$, respectivamente.

Segundo MacDonald et al. (1991), durante o processo de ensilagem do milho, ocorre diminuição dos teores de FDN. Tal fato pode estar associado à hidrólise da fração hemicelulose, devido à ação da hemicelulase, bem como da hidrólise ácida, podendo tornar mais disponível a fração fibrosa das silagens estudadas para os microrganismos do rúmen.

A fração $a$ do amido da SRp foi maior que as da SMi e da SCc e a fração $b$, menor que as outras silagens. Porém, as DP foram semelhantes entre os tratamentos e o valor de DE (Kp 5\%/h) do amido da SRp, que foi superior ao das demais, o que, provavelmente, se deve à alta kd do amido da SRp.

Analisando os parâmetros de degradação do amido da SRp, observa-se que tanto o valor da fração $a$ quanto o valor da taxa de degradação da fração $b$ foram menores e maiores, respectivamente, que os encontrados por Martins (1999), de 52,0\% e 6,7\%/h, e Caldas Neto (2000) de 51,1\% e 9,0\%/h. A DE (Kp $5 \% / \mathrm{h}$ ) do amido da SRp foi maior que a de 70,4\% encontrada por Martins (1999) e próxima à de 81,2\% encontrada por Caldas Neto (2000).

Os valores da fração $a$ e da kd do amido da SCc foram menores que os encontrados por Caldas Neto
(2000), de 32,0\% e 3,0\%/h, respectivamente. Ao contrário da fração $b$ e da DE (Kp 5\%), que tiveram valores maiores que os encontrados também por Caldas Neto (2000), de 67,9 e 56,8\%, respectivamente.

Como o amido da mandioca apresenta maior concentração de amilopectina que de amilose (Vilela \& Ferreira, 1987) e a amilopectina não é solúvel em água, não se justificaria a presença de valores altos da fração $a$. Entretanto, a solubilidade do amido pode ainda ser favorecida pela ação de ácidos provenientes de sua fermentação, que atuariam rompendo as pontes de hidrogênio, principalmente da amilopectina (Van Soest, 1994). Observando-se os valores de $\mathrm{pH}$ das silagens (Tabela 2), nota-se que a SRp apresentou menor valor de $\mathrm{pH}$ e, conseqüentemente, maior valor de fração solúvel do amido, o mesmo aconteceu com as outras silagens de milho e de casca de mandioca.

Os valores de $\mathrm{pH}$ ruminal dos animais nos diferentes tratamentos podem ser observados na Figura 1. Todos os valores médios de pH estão próximos a 6,0 , com exceção dos observados nos animais alimentados com $\mathrm{SCn}$, os quais foram próximos de 7,0. Segundo Coelho \& Leão (1979), valores de pH inferiores a 6,0 podem acarretar diminuição da atividade das bactérias fibrolíticas, reduzindo, conseqüentemente, a degradação da fibra.

Não houve diferença $(\mathrm{P}>0,05)$ entre os valores de $\mathrm{pH}$ obtidos nos diferentes horários de coleta de líquido ruminal em todos os tratamentos.

Quanto às SMi, SRp e SCc, todas não diferiram entre si $(\mathrm{P}>0,05)$ em relação ao $\mathrm{pH}$. Todavia, no tratamento com $\mathrm{SCn}$, o $\mathrm{pH}$ ruminal foi superior aos dos demais, provavelmente, devido à maior quantidade de uréia utilizada nesta dieta (Tabela 3). A solubilidade da uréia e sua rápida hidrólise para a forma de amônia tendem a manter o $\mathrm{pH}$ ruminal elevado (Lucci, 1997).

Fregadolli (2000) e Caldas Neto (2000), trabalhando com casca de mandioca desidratada, encontraram valores médios de $\mathrm{pH}$ entre 6,1 e 6,7, os quais estão bem próximos dos encontrados no presente trabalho $(6,1$ a 6,5$)$.

Carmo (1999), trabalhando com bovinos alimentados com cana-de-açúcar fresca, picada e suplementados com uréia, farelo de soja ou glúten de milho, observou valor médio de $\mathrm{pH}$ de 6,8 para o tratamento com uréia, valor bem próximo ao encontrado para SCn de 6,66. 


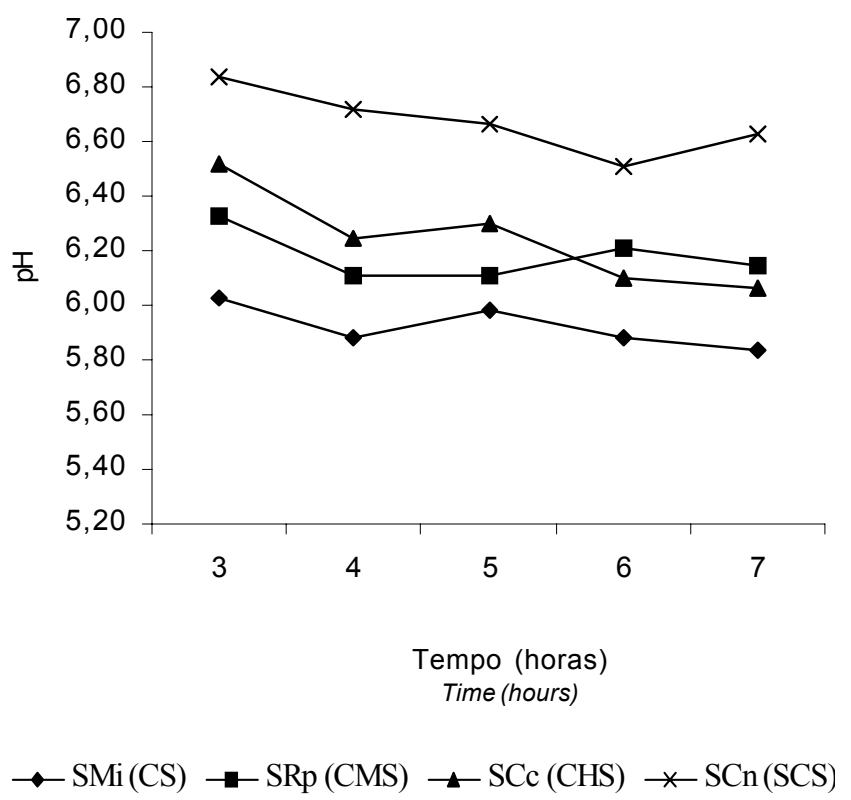

Figura 1 - Valores médios de $\mathrm{pH}$ do líquido ruminal em função do tempo após a alimentação para os tratamentos com silagens de milho (SMi), de raspa de mandioca com polpa cítrica (SRp), de casca de mandioca com polpa cítrica (SCc) e de cana-de-açúcar com polpa cítrica (SCn) $(\mathrm{CV}=6,69 \%)$.

Figure 1 - Average values of rumen fluid $\mathrm{pH}$, as a function of the time after intake, for each treatment with Corn silage (CS), Cassava meal ensiled with citrus pulp (CMS), Cassava hull ensiled with citrus pulp (CHS) and Sugar cane ensilated with citrus pulp (SCS).

Para as concentrações de $\mathrm{N}-\mathrm{NH}_{3}$ ruminal, pode-se observar diminuição na concentração em todos os tratamentos, de acordo com o distanciamento dos horários de alimentação (Figura 2). Os valores médios encontrados foram 11,66; 13,64; 17,28; e 22,64 mg $\mathrm{N}-\mathrm{NH}_{3} / 100 \mathrm{~mL}$ de líquido ruminal, para SMi, SRp, $\mathrm{SCc}$ e SCn, respectivamente. As concentrações de nitrogênio amoniacal foram suficientes para suportar o crescimento bacteriano, conforme valor mínimo citado por Preston (1986), de $5 \mathrm{mg} \mathrm{N}-\mathrm{NH}_{3} / 100 \mathrm{~mL}$. Entretanto, para otimizar a taxa de desaparecimento da celulose e da fibra dos alimentos incubados em sacos de náilon no rúmen, este valor se mostrou baixo, sendo que bons resultados foram observados quando a concentração de nitrogênio amoniacal ruminal foi elevada para $20 \mathrm{mg} \mathrm{N}-\mathrm{NH}_{3} / 100 \mathrm{~mL}$. De acordo com o referido autor, valores entre 15 e $29 \mathrm{mg} \mathrm{N}-\mathrm{NH}_{3} / 100 \mathrm{~mL}$ podem ser necessários para a ótima fermentação de

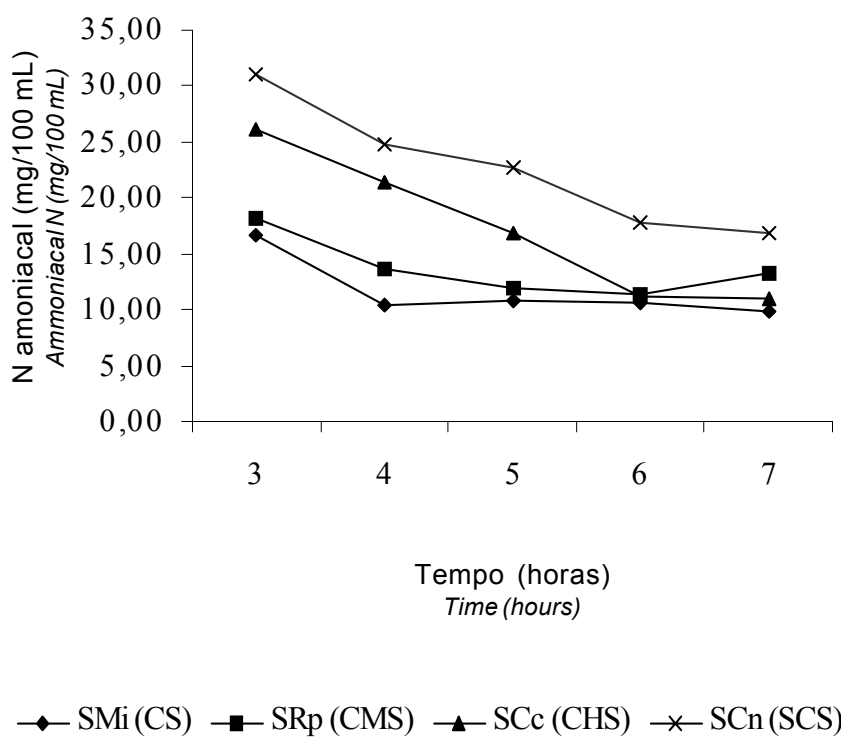

Figura 2 - Concentração de nitrogênio amoniacal $\left(\mathrm{N}-\mathrm{NH}_{3}\right.$ $\mathrm{mg} / 100 \mathrm{~mL}$ ) do líquido ruminal em função do tempo após a alimentação para os tratamentos com silagens de milho (SMi), de raspa de mandioca com polpa cítrica (SRp), de casca de mandioca com polpa cítrica (SCc) e de cana-de-açúcar com polpa cítrica (SCn) (CV= $27.05 \%)$.

Figure 2 - Ammoniacal nitrogen concentration $\left(\mathrm{N}-\mathrm{NH}_{3} \mathrm{mg} / 100\right.$ $m L)$, as a function of the time after intake, for each treatment with Corn silage (CS), Cassava meal ensiled with citrus pulp (CMS), Cassava hull ensiled with citrus pulp (CHS) and Sugar cane ensilated with citrus pulp (SCS).

alimentos fibrosos. No presente experimento, foram encontrados valores médios inferiores, apenas para os tratamentos SMi e SRp, de 11,66 e 13,65 mg N-NH $\mathrm{NH}_{3}$ $100 \mathrm{~mL}$ de líquido ruminal.

Os maiores valores encontrados de $\mathrm{N}-\mathrm{NH}_{3}$ foram para $\mathrm{SCn}$, provavelmente devido à maior quantidade de uréia fornecida na ração para os animais (Tabela 3).

A concentração $\mathrm{N}^{-\mathrm{NH}_{3}}$ no líquido ruminal é conseqüência do equilíbrio entre sua produção, absorção e utilização pelos microrganismos, sendo a última dependente da quantidade de energia disponível. A maioria das bactérias ruminais são capazes de utilizar $\mathrm{N}-\mathrm{NH}_{3}$ como fonte de nitrogênio para síntese de proteína microbiana, mas a fermentação ruminal da proteína, freqüentemente, produz mais $\mathrm{N}-\mathrm{NH}_{3}$ que os microrganismos podem utilizar.

As concentrações molares dos ácidos graxos vo- 
láteis (AGV), bem como a relação acetato:propionato, para cada dieta, encontram-se na Tabela 5.

Para todas as variáveis apresentadas anteriormente, pode-se observar que os valores obtidos para SMi, SRp e SCc foram semelhantes e superiores em relação ao tratamento com $\mathrm{SCn}$.

A relação acetato:propionato encontrada no presente trabalho para os tratamentos com $\mathrm{SMi}$, SRp e SCc foi inferior aos 5,1 por Berchielli et al. (1996), trabalhando com a concentração e proporção molar de AGV em bovinos alimentados com diferentes níveis de concentrados (farelo de algodão, milho e uréia) e usando silagem de milho como volumoso, porém este valor está próximo aos 5,23 para o tratamento com SCn.

Vários estudos (Joy et al., 1997; Lycos et al.,
1997) também não observaram diferenças nas concentrações de ácidos graxos voláteis totais em dietas que variaram na proporção de amido degradável no rúmen.

A utilização única da uréia no tratamento com SCn não acarretou aumento das concentrações de acetato, propionato, iso-butirato, butirato, iso-valerato, valerato e de AGV total no fluído ruminal, com relação aos outros tratamentos. Por ser uma fonte de $\mathrm{N}$ de alta solubilidade, a uréia foi disponibilizada logo nos primeiros tempos após a ingestão, além disso, houve provavelmente fornecimento de energia inadequado, prejudicando a fermentação microbiana e, conseqüentemente, diminuindo a produção de $\mathrm{AGV}$ (Lucci, 1997).

Tabela 5 -Concentração média de ácidos graxos voláteis $(\mathrm{mmol} / \mathrm{mL})$, relação acetato:propionato e proporção molar (\%), em função das dietas utilizadas

Table 5 - Average concentration of volatile fatty acids ( $\mathrm{mmol} / \mathrm{mL})$, acetate:propionate ratio and molar proportions (\%), in fuction of the diets

\begin{tabular}{|c|c|c|c|c|}
\hline \multirow[t]{2}{*}{$\begin{array}{l}\text { Parâmetros } \\
\text { Parameters }\end{array}$} & \multicolumn{4}{|c|}{$\begin{array}{c}\text { Dietas } \\
\text { Diets }\end{array}$} \\
\hline & SMi (CS) & $\operatorname{SRp}(C M S)$ & $\mathrm{SCc}(\mathrm{CHS})$ & $\mathrm{SCn}(S C S)$ \\
\hline \multicolumn{5}{|c|}{$\begin{array}{l}\text { Concentração de } \mathrm{AGV}(\mathrm{mmol} / \mathrm{mL}) \\
\text { VFA concentration }(\mathrm{m} \mathrm{mol} / \mathrm{mL})\end{array}$} \\
\hline $\begin{array}{l}\text { Acetato } \\
\text { Acetate }\end{array}$ & 74,35 & 75,93 & 74,04 & 65,20 \\
\hline $\begin{array}{l}\text { Propionato } \\
\text { Propionate }\end{array}$ & 19,82 & 18,91 & 18,21 & 12,47 \\
\hline $\begin{array}{l}\text { Relação acetato:propionato } \\
\text { Acetate:propionate ratio }\end{array}$ & 3,75 & 4,01 & 4,06 & 5,23 \\
\hline $\begin{array}{l}\text { Iso-Butirato } \\
\text { Iso-Butirate }\end{array}$ & 0,73 & 0,41 & 0,61 & 0,26 \\
\hline $\begin{array}{l}\text { Butirato } \\
\text { Butirate }\end{array}$ & 10,75 & 9,93 & 10,46 & 7,99 \\
\hline $\begin{array}{l}\text { Iso-Valerato } \\
\text { Iso-Valerate }\end{array}$ & 1,23 & 0,53 & 0,90 & 0,28 \\
\hline $\begin{array}{l}\text { Valerato } \\
\text { Valerate }\end{array}$ & 1,40 & 1,08 & 1,32 & 0,79 \\
\hline $\begin{array}{l}\text { AGV Ruminal Total } \\
\text { Ruminal VFA Total } \\
\text { Proporção molar (\%) } \\
\text { Molar nronortion } \% \text { ) }\end{array}$ & 108,28 & 106,80 & 105,54 & 86,99 \\
\hline $\begin{array}{l}\text { Molar proportion (\%) } \\
\text { Acetato } \\
\text { Acetate }\end{array}$ & 68,66 & 71,10 & 70,15 & 74,95 \\
\hline $\begin{array}{l}\text { Propionato } \\
\text { Propionate }\end{array}$ & 18,30 & 17,71 & 17,25 & 14,33 \\
\hline
\end{tabular}




\section{Conclusões}

A silagem de raspa de mandioca com polpa cítrica foi a que apresentou maior degradação em relação as demais dietas.

Para todos os tratamentos, o pH e a concentração de $\mathrm{N}-\mathrm{NH}_{3}$ ruminal foram adequados para o crescimento dos microrganismos ruminais.

Os valores de AGV para os tratamento de $\mathrm{SMi}$, SRp e SCc foram semelhantes entre si e superiores ao do tratamento com SCn.

\section{Literatura Citada}

AGRICULTURAL AND FOOD RESEARCH COUNCIL AFRC. Technical committee on responses to nutrients: energy and protein requirements of ruminants. Wallingford: Cab International, 1995. 159p.

ANDRADE, P. Técnica in situ (saco de náilon) na avaliação de alimentos para ruminantes. In: SIMPÓSIO INTERNACIONAL DE PRODUÇÃO DE RUMINANTES; REUNIÃO ANUAL DA SOCIEDADE BRASILEIRA DE ZOOTECNIA, 31., Maringá. Anais... Maringá: Sociedade Brasileira de Zootecnia, 1994. p.141-147.

ASSOCIATION OF OFFICIAL ANALYTICAL CHEMISTRY AOAC. Official methods of analysis. Washington, D.C.: 1990. 1298p.

ARCURY, P.B.; MATTOS, L.L. Microbiologia do rúmen. Informe Agropecuário, v.16, n.5, p.5-8, 1992.

BERCHIELLI, T.T.; RODRIGUES, N.M.; ANDRADE, P. Concentração, proporção molar e taxa de produção de ácidos graxos voláteis (AGV) no rúmen de bovinos alimentados com diferentes níveis de concentração na dieta. Revista Brasileira de Zootecnia, v.25, n.3, p.511-521, 1996.

CALDAS NETO, S.F. Digestibilidade parcial e total, parâmetros ruminais e degradabilidade de rações com mandioca e resíduos das farinheiras. Maringá: Universidade Estadual de Maringá, 2000. 66p. Dissertação (Mestrado em Zootecnia) - Universidade Estadual de Maringá, 2000.

CARMO, C.A. Degradabilidade da matéria seca e fibra em detergente neutro da cana-de-açúcar (Saccharum spp) com diferentes fontes de proteína. Jaboticabal, Universidade Estadual Paulista, 1999. 36p. Monografia (Graduação em Zootecnia) - Universidade Estadual Paulista, 1999.

COELHO, J.F.S.; LEÃO, M.I. Fundamentos de nutrição de ruminantes. Piracicaba: Livroceres, 1979. 380p.

FRANZOLIN, R.; FRANZOLIN, M.H.T. População protozoários ciliados e degradabilidade ruminal em búfalos e bovinos zebuínos sob dieta à base de cana-de-açúcar. Revista Brasileira de Zootecnia, v.29, n.6. p.1853-1861, 2000.

FREGADOLLI, F.L. Efeitos da degradabilidade ruminal do amido e do nitrogênio da dieta sobre o metabolismo ruminal e a digestibilidade em bovinos. Maringá, Universidade Estadual de Maringá, 2000. 68p. Dissertação (Mestrado em Zootecnia) - Universidade Estadual de Maringá, 2000.

FURLAN, C.L.F. Estimativa da disponibilidade da forragem, composição da extrusa e consumo de matéria seca de vacas em lactação sob pastejo intensivo de capim
“coastcross"(Cynodon dactylon (1.) Pers). Jaboticabal: Universidade Federal de São Paulo, 1998. 75p. Dissertação (Mestrado em Zootecnia) - Universidade Estadual Paulista, 1998.

JOY, M.T.; DePETTERS, J.; FADEL, J.G. et al. Effects of corn processing on the site and extern of digestion in lactating cows. Journal of Dairy Science, v.80, p.2087-2097, 1997.

LYCOS, T.; VARGA, G.A.; CASPER, D. Varying degradation rates of total nonstructural carbohydrates: Effects on ruminal fermentation, blood metabolites, and milk production and composition in high producing Holstein cows. Journal of Dairy Science, v.80, p.3341-3355, 1997.

LUCCI, C.S. Nutrição e manejo de bovinos leiteiros. São Paulo: Manole, 1997. 169p.

MARTINS, A.S. Desempenho de novilhas alimentadas com rações contendo milho ou casca de mandioca e farelo de algodão ou levedura. Maringá: Universidade Estadual de Maringá, 1999. 84p. Dissertação (Mestrado em Zootecnia) - Universidade Estadual de Maringá, 1999.

MacDONALD, P.; HENDERSON, N.; HERON, S. The biochemistry of silage. Marlow Bucks: Chalcombe Publications, 1991. 340p.

MEHREZ, A.Z.; ØRSKOV, E.R. A study of the artificial fibre bag technique for determining the digestibility of feeds in the rumen. Journal of Agriculture Science, v.88, n.4, p.645-65, 1977.

$\varnothing$ RSKOV, E.R.; McDONALD, I. The estimation of protein degradability in the rumen from incubation measurements weighted according to rate of passage. Journal of Agriculture Science, v.92, n.2, p.499-502, 1979.

PEREIRA, J.R.A, ROSSI JR., P. Manual prático de avaliação nutricional de alimentos. Piracicaba: Fundação de Estudos Agrários "Luiz de Queiroz", 1995. 25p.

POORE, M.H., ECK, T.P., SWINGLE, R.S. et al. Total starch and relative starch availability of feed grams. In: BIENAL CONFERENCE ON RUMEN FUNCTION, 1989, Chicago. Proceedings... Chicago: 1989.

PRESTON, T.R. Analytical methods for characterizing In: feed resourses for ruminants. Better utilization of crop residues and by products in animal feeding: research guidelines. A practical manual for research workers. Rome: FAO, 1986. p. 106.

SAS INSTITUTE. SAS users'guide: statistics. 5.ed. Cary: 1985. v.1, 956p.

VALADARES FILHO, S.C. Utilização da técnica in situ para avaliação dos alimentos. In: SIMPÓSIO INTERNACIONAL DE PRODUÇÃO DE RUMINANTES; REUNIÃO ANUAL DA SOCIEDADE BRASILEIRA DE ZOOTECNIA, 31., Maringá. Anais... Maringá: Sociedade Brasileira de Zootecnia, p.95-118, 1994.

Van SOEST, P.J. Nutritional ecology of the ruminant. New York, 1994. 476p.

VILELA, E.R.; FERREIRA, M.E. Tecnologia de produção e utilização do amido de mandioca. Informe Agropecuário, v.13, n.145, p.69-73, 1987.

Recebido em: 19/06/01 Aceito em: 03/12/01 